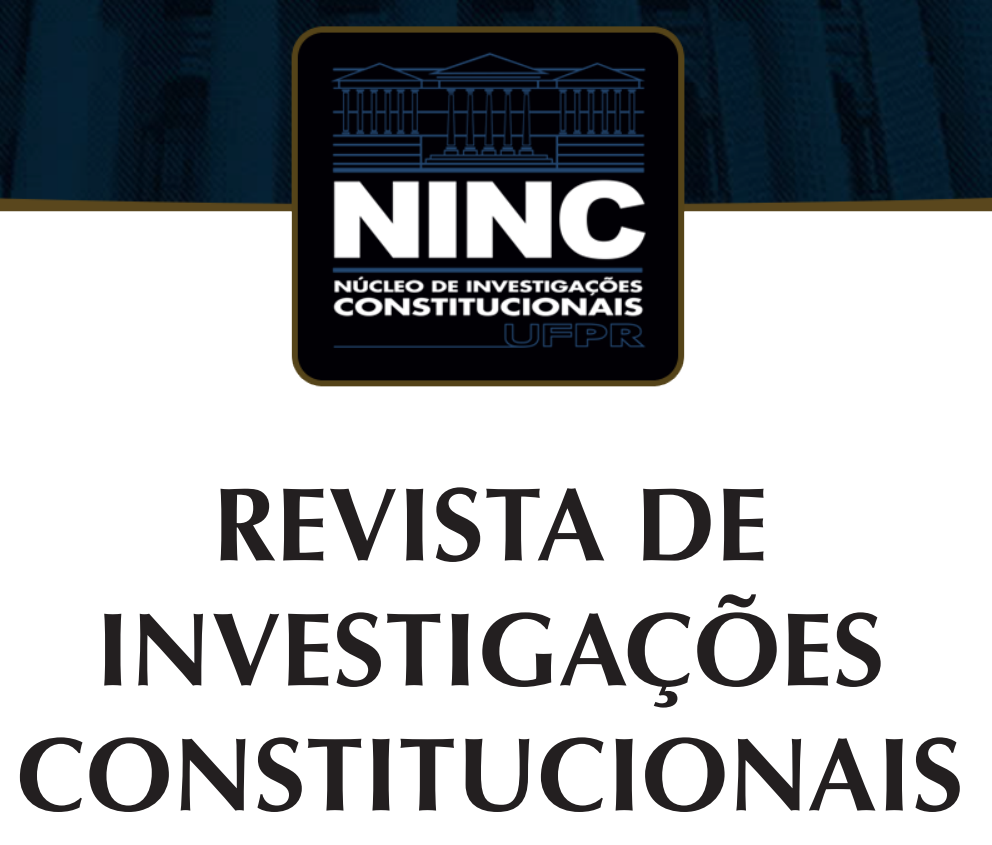

JOURNAL OF CONSTITUTIONAL RESEARCH

vol. 8 | n. 3 | setembro/dezembro 2021 | ISSN 2359-5639 | Periodicidade quadrimestral Curitiba | Núcleo de Investigações Constitucionais da UFPR | www.ninc.com.br 


\title{
Supremacía constitucional, jerarquía normativa y derechos humanos en México: evolución jurisprudencial histórica y narrativas actuales
}

\section{Constitutional supremacy, normative hierarchy, and human rights in Mexico: historical jurisprudential evolution and current narratives}

\author{
OCTAVIO RODRÍGUEZ FERREIRA 1 ," \\ 'University of San Diego (San Diego, Estados Unidos de América) \\ orodriguez@sandiego.edu \\ https://orcid.org/0000-0003-2291-9379 \\ Recebido/Received: 22.09.2020 / September 22 $2^{\text {th }}, 2020$ \\ Aprovado/Approved: 07.05.2021 / May $7^{\text {th }}, 2021$
}

Resumen

Este artículo desarrolla un análisis histórico de la relación y recepción del derecho internacional y sus instrumentos en el derecho interno mexicano a través de la práctica jurisprudencial. A partir de ello, evidencia un cierto desequilibrio jurídico-institucional debido a posturas garantistas y favorables a derechos humanos, frente a interpretaciones restrictivas o limitativas. En última instancia el artículo pretende evidenciar como las narrativas actuales respecto a la supremacía constitucional y la jerarquía normativa en México no son del todo acordes con la realidad globalizada de los derechos humanos actuales.

Palabras clave: derechos humanos; supremacía constitucional; jerarquía normativa; derecho internacional; jurisprudencia.
Abstract

This article develops a historical analysis of the relationship and reception of international law and its instruments in Mexican domestic law through its jurisprudential practice. Building on this, it shows a certain legal-institutional imbalance due to human rights-favorable perspectives in front of restrictive or limiting interpretations. Ultimately, the article aims to show how current narratives on constitutional supremacy and normative hierarchy in Mexico are not entirely consistent with the current globalized human rights reality.

Keywords: human rights; constitutional supremacy; normative hierarchy; international law; jurisprudence.

Como citar esse artigo/How to cite this article: RODRÍGUEZ FERREIRA, Octavio. Supremacía constitucional, jerarquía normativa y derechos humanos en México: evolución jurisprudencial histórica y narrativas actuales. Revista de Investigações Constitucionais, Curitiba, vol. 8, n. 3, p. 679-705, set./dez. 2021. DOI: 10.5380/rinc.v8i3.76714.

"Profesor e investigador en el Departamento de Ciencias Políticas y Relaciones Internacionales, y Profesor Adjunto en la Facultad de Derecho de la University of San Diego (San Diego, Estados Unidos de América). Director Ejecutivo del Programa Justice in Mexico. Es Licenciado en Derecho, Maestro en Ciencias Jurídicas y Doctor en Derecho por la Universidad Panamericana. E-mail: orodriguez@sandiego.edu. 


\section{SUMARIO}

1. Introducción; 2. Supremacía constitucional, jerarquía normativa y derechos humanos en México; 2.1. Supremacía constitucional; 2.2. Supremacía constitucional y jerarquía normativa en el constitucionalismo histórico; 2.2.1. Tratados internacionales y jerarquía normativa; 2.3. Los derechos humanos en el marco jurídico vigente; 2.3.1. Sistema de justicia penal acusatorio; 2.3.2. Efectos 'erga omnes' del amparo; 3. Supremacía constitucional y la jerarquía normativa en la historia jurisprudencial de México; 3.1. La narrativa tradicional y originalista; 3.2. Una incipiente apertura; 3.3. La consolidación global del derecho internacional; 3.4. Hacia un cambio de paradigma; 3.4.1. Control constitucional y convencional a partir del caso Radilla; 3.4.2. Igualdad jerárquica de los tratados de derechos humanos y de la Constitución; 3.5. Ad Contradictio: de vuelta al statu quo ante; 3.5.1. Configuración de una 'nueva' narrativa: la C.T. 293/11; 3.5.2. La narrativa de la "regularidad constitucional" y del "bloque de constitucionalidad"; 3.5.3. La 'nueva' jerarquía normativa en México; 4. Reflexiones sobre las 'nuevas' narrativas de la supremacía constitucional y de la jerarquía normativa en México; 5. Consideraciones Finales; 6. Referencias.

\section{INTRODUCCIÓN}

El sistema constitucional mexicano conserva una relativa rigidez respecto al derecho internacional, así como respecto a la forma en cómo interactúan sus instrumentos en el marco jurídico interno. Es más, esta interacción resulta bastante confusa y ambigua, sujeta a constantes cambios, tanto en el ámbito legislativo, como en el jurisprudencial. Ya que la Constitución mexicana no incluye alguna disposición que indique la manera precisa en cómo los instrumentos de derecho internacional son recibidos en el derecho interno, esto dificulta la operatividad de las normas internacionales, sobre todo aquellas relativas a derechos humanos.

El artículo 133 constitucional-que contiene los criterios de jerarquía normativa, el parámetro de regularidad y el principio de supremacía constitucional—no ha sufrido modificación sustancial desde la constitución de 1857 . Su redacción, no especifica la forma en que los tratados serán utilizados e interpretados en relación con los otros cuerpos normativos considerados "ley suprema" de la Unión. Más aún, este precepto, conceptualizado en el siglo XVIII, no parece ya suficiente para interpretar la nueva realidad de un mundo globalizado, y mucho menos la expansión progresiva de los derechos humanos, generada mayormente a través de tratados y por organismos internacionales.

Es precisamente en el ámbito jurisprudencial donde es más claro cómo la evolución histórica del derecho internacional y la consolidación progresiva de los derechos humanos en ocasiones contrasta con la rigidez constitucional mexicana, y con algunos de sus principios fundamentales, como lo es la supremacía constitucional. En este artículo desarrollo un recorrido histórico de la interpretación del statu jurídico del derecho internacional y sus instrumentos, en el derecho mexicano, a través de la práctica 
jurisprudencial. Finalmente busco evidenciar cómo las narrativas acuales de la jerarquía normativa y de la supremacía constitucional no son del todo acordes con la realidad globalizada de los derechos humanos actuales.

\section{SUPREMACÍA CONSTITUCIONAL, JERARQUÍA NORMATIVA Y DERECHOS HUMANOS EN MÉXICO}

Como preámbulo teórico, es importante hacer una revisión de los conceptos más importantes que se han contrapuesto a lo largo de la historia constitucional y jurisprudencial mexicana, cuando el derecho interno y el derecho internacional se interrelacionan.

\subsection{Supremacía constitucional}

El concepto de supremacía constitucional es uno de los basamentos más importantes del constitucionalismo moderno. Su configuración formal se puede remontar hasta la redacción del artículo VI de la Constitución de los Estados Unidos en 1789. ${ }^{1}$ El principio se entiende, comúnmente, como aquella cualidad o estado de ser supremo o superior en rango o autoridad. Sin embargo la "cláusula de supremacía" ideada por el constituyente estadounidense, debería entenderse desde dos diferentes ángulos: el primero, que captura la concepción más común de supremacía, que considera a la Constitución como el instrumento jurídico de mayor rango y autoridad, en tanto que busca conservar las estructuras gubernamentales, subordinando a las entidades federativas a la autoridad delegada al gobierno federal; $y$, la segunda, que sugiere que las decisiones de los poderes judiciales federales respecto a cuál es la ley suprema, tendrán primacía sobre aquellas que hicieran los juzgadores estatales. ${ }^{2}$

La doctrina mexicana ha concebido el principio como que la constitución es la ley suprema y ordenamiento cúspide de todo el derecho, ${ }^{3}$ y que cualquier norma contraria no tiene posibilidad de existencia dentro de dicho orden. ${ }^{4}$ Burgoa, basándose en Kelsen, explica que la Constitución "es la base y la cumbre, lo fundatorio y lo insuperable, dentro de cuyos extremos se mueve toda la estructura vital del Estado" ("Super

\footnotetext{
La cláusula de supremacía tiene su antecedente precisamente en el artículo VI de la Constitución de los Estados Unidos, el cual establece a grandes rasgos lo siguiente: La Constitución y las leyes que se realicen en virtud de la misma, y todos los tratados celebrados o que se celebren bajo la autoridad de los Estados Unidos, serán la ley suprema de la nación; y los jueces de cada estado estarán obligados a ella de la misma forma, a pesar de cualquier disposición en contrario en las constituciones o las leyes de cualquier estado. Traducción personal. The Constitution of the United States of America. United States of America: 1789.

2 SAMAR, Vincent. Two Understandings of Supremacy: An Essay. Richmond Journal of Global Law and Business, vol. 9, n. 4, p. 339-380, 2010. p. 339.

3 BURGOA, Ignacio. Derecho Constitucional Mexicano. 8. ed. México: Porrúa, 1991. p. 359.

4 CARPIZO, Jorge. La interpretación del artículo 133 constitucional. Boletín Mexicano de Derecho Comparado, Nueva Serie, año II, n. 4, ene./abr., 1969. p. 3.
} 
constitutionem, nihil; sub constitutione, omnia"). ${ }^{5}$ La supremacía constitucional presupone como condiciones que el poder constituyente sea distinto a los poderes constituidos, y que la Constitución sea rígida y estricta. ${ }^{6}$

El artículo 133 de la Constitución mexicana consagra dicho principio de la siguiente manera:

Esta Constitución, las leyes del Congreso de la Unión que emanen de ella y todos los tratados que estén de acuerdo con la misma, celebrados y que se celebren por el presidente de la república, con aprobación del Senado, serán la ley suprema de toda la Unión. Los jueces de cada Estado se arreglarán a dicha Constitución, leyes y tratados, a pesar de las disposiciones en contrario que pueda haber en las Constituciones o leyes de los Estados.

En efecto, el principio de supremacía constitucional obedece a un contexto histórico en el que se buscaba generar cohesión y aportar estructuras gubernamentales sólidas a unidades sub-nacionales. La supremacía era la garantía de unidad, por medio de la cual las entidades federativas otorgaban una autoridad suprema al texto fundamental federal. Lo anterior es evidente en los Estados Unidos, en el contexto en que la federación debía establecer una preeminencia jurídica sobre los poderes fácticos que, en efecto, tenían los estados de la unión. Es claro que el contexto en el que surge dicho principio contemplaba principalmente los posibles conflictos legislativos en un estado federal y no necesariamente una interacción entre ordenamientos jurídicos supranacionales. Sería complicado imaginarse cuál sería la postura de los redactores de esos textos constitutivos y de sus principios, ante el entorno globalizado actual. ${ }^{7}$

\subsection{Supremacía constitucional y jerarquía normativa en el constitu- cionalismo histórico}

El primer texto fundamental de México como nación independiente, el “Decreto Constitucional para la Libertad de la América Mexicana"—también conocido como Decreto de Apatzingán—de 1814 contiene de manera muy primaria las raíces del principio de supremacía en el artículo 237, estipulando la observancia inviolable del documento hasta la promulgación de una constitución permanente. ${ }^{8}$ Posteriormente el

\footnotetext{
5 "Sobre la constitución nada; bajo la Constitución todo". Máxima atribuida a José María Iglesias. BURGOA, Ignacio. Derecho Constitucional Mexicano. 8. ed. México: Porrúa, 1991. p. 359.

TENA RAMÍREZ, Felipe. Derecho Constitucional Mexicano. 32. ed. México: Porrúa, 1998. p. 12.

SAMAR, Vincent. Two Understandings of Supremacy: An Essay. Richmond Journal of Global Law and Business, vol. 9, n. 4, p. 339-380, 2010. p. 339. Ramsey propone que las discrepancias entre una interpretación literal y originalista de la cláusula de supremacía con aquellas del derecho modelo pueden resolverse, manteniendo la primera, pero haciendo uso de otros recursos jurídicos. RAMSEY, Michael D. The Supremacy Clause, Original Meaning, and Modern Law. Ohio State Law Journal, vol. 74, n. 4, 2013. passim.

8 "Entretanto que la Representación nacional, de que trata el capítulo antecedente, no fuere convocada, y siéndolo, no dictare y sancionare la Constitución permanente de la Nación, se observará inviolablemente
} 
Acta Constitutiva de la Federación Mexicana de 1824 en el artículo 24, ya reconoce de manera más precisa la supremacía del Acta y la Constitución general por sobre las de los estados. ${ }^{9}$

Es hasta la Constitución Federal de los Estados Unidos Mexicanos de 1824 que se reconoce ya autoridad a los tratados internacionales al estipular en el artículo 161III la obligación de los estados de guardar y hacer guardar la Constitución, las leyes generales y los tratados. ${ }^{10}$ Posteriormente el Acta Constitutiva y de Reformas de 1847 regresaría a una concepción más primigenia del principio de supremacía, ya que el artículo tercero únicamente establece que todos los poderes públicos se arreglarán a la Constitución. ${ }^{11}$

La Constitución de 1857 da su forma 'definitiva' al principio de supremacía constitucional y a la jerarquía normativa. El artículo 126 menciona a la Constitución, a las leyes federales y a los tratados internacionales, como ley suprema de la Unión, y obliga a los jueces de los estados a "arreglarse" a ellas a pesar de disposición en contrario en la legislación estatal. ${ }^{12}$

La Constitución de 1857 fue la base para la Constitución Política de los Estados Unidos Mexicanos de 1917-vigente hasta nuestros días. ${ }^{13}$ El principio de supremacía constitucional y la jerarquía normativa fueron incluidos, casi sin modificación, en

al tenor de este decreto, y no podrá proponerse alteración, adición ni supresión de ninguno de los artículos en que consiste esencialmente la forma de gobierno que prescribe. Cualquier ciudadano tendrá derecho de reclamar las infracciones que notare". TENA RAMÍREZ, Felipe. Leyes Fundamentales de México 1808 - 1997. 20. ed. México: Porrúa, 1997. p. 57.

9 "Las Constituciones de los Estados no podrán oponerse a esta acta ni a lo que establezca la Constitución general: por tanto, no podrán sancionarse hasta la publicación de esta última". TENA RAMÍREZ, Felipe. Leyes Fundamentales de México 1808 - 1997. 20. ed. México: Porrúa, 1997, p. 158.

10 "Cada uno de los Estados tiene obligación [...] [d] guardar y hacer guardar la constitución y leyes generales de la Unión, y los tratados hechos o que en adelante se hicieren por la autoridad suprema de la federación con alguna potencia extranjera". TENA RAMÍREZ, Felipe. Leyes Fundamentales de México 1808 - 1997. 20. ed. México: Porrúa, 1997, p. 191.

11 "Publicada esta Acta de reformas, todos los Poderes públicos se arreglarán á ella [...] Los Estados continuarán observando sus constituciones particulares y conforme á ellas renovarán sus poderes [sic]". TENA RAMÍREZ, Felipe. Leyes Fundamentales de México 1808 - 1997. 20. ed. México: Porrúa, 1997, p. 476.

12 “Esta Constitución, las leyes del Congreso de la Unión que emanen de ella y todos los tratados hechos ó que se hicieren por el Presidente de la República, con aprobación del Congreso, serán la ley suprema de toda la Unión. Los jueces de cada Estado se arreglarán á dicha Constitución, leyes y tratados, á pesar de las disposiciones en contrario que pudiera haber en las constituciones ó leyes de los Estados [sic]". TENA RAMíREZ, Felipe. Leyes Fundamentales de México 1808 - 1997. 20. ed. México: Porrúa, 1997, p. 627.

13 Con la instauración del Segundo Imperio Mexicano entre 1863 y 1867, se abrogó la Constitución de 1857 y en su lugar se expidió el "Estatuto Provisional del Imperio Mexicano". Su texto de corte imperial adopta una interpretación más central y rígida de la supremacía, estableciendo en el artículo 80 que "[t]odas las leyes y decretos que en lo sucesivo se espidieren, se arreglarán á las bases fijadas en el [...] Estatuto, y las autoridades quedan reformadas conforme á él [sic]". Estatuto Provisional del Imperio Mexicano. México: 1865. Con la caída del imperio, se restableció la autoridad de la Constitución de 1857. 
el artículo 133, y su redacción se mantuvo sin cambios hasta 1934 cuando ocurrió su primera y única reforma. ${ }^{14}$

El artículo 133, sin embargo, no estipula claramente cuál es la jerarquía entre los ordenamientos que se consideran "ley suprema”, por lo que ha correspondido a la jurisprudencia determinar la manera en que los tratados internacionales interactúan con, y se incorporaran al derecho interno en atención los principios de supremacía constitucional y de jerarquía normativa.

\subsubsection{Tratados internacionales y jerarquía normativa}

Los sistemas constitucionales estrictos o cerrados, como es el caso de México, conciben a los tratados internacionales como actos jurídicos que son regidos por el derecho internacional público que requieren de una incorporación expresa al derecho interno para poder ser vinculantes para sus autoridades y ciudadanos. ${ }^{15}$ De tal forma, los tratados internacionales pueden considerarse solamente válidos mediante un acto legislativo que les otorgue validez plena, y que propicie las reformas necesarias para adaptar el sistema jurídico a sus disposiciones. ${ }^{16}$

Antes de que un tratado forme parte del orden jurídico interno, debe, entonces, ser aprobado por el Senado, proceso "en virtud del cual se aceptan los términos del pacto negociado por el Presidente [...], razón por la cual ésta es necesaria para que un tratado pueda ser ratificado y, en consecuencia, para que entre en vigor". ${ }^{17}$ Una vez cumplidas las formalidades-incluida su publicación en el Diario Oficial de la Federación [referido también como DOF] - el texto del tratado se convierte en parte integrante del marco jurídico mexicano de acuerdo al artículo 133 Constitucional.

Sin embargo, como ya señalé anteriormente, el artículo 133 no delimita-per se-los alcances de jerarquía de las leyes consideradas "supremas". La redacción del artículo presenta varios cuestionamientos, como son: la supremacía o competencias del derecho federal sobre el local; la jerarquía de las normas supremas entre ellas; la calidad o no de los tratados como normas fundamentales; la aplicación de uno u otro

\footnotetext{
14 Dicha reforma se encargó de precisar algunos puntos con relación a los tratados, como el cambio de las palabras "hechos y que se hicieren" por "celebrados y que se celebren". De manera importante se precisó que los tratados deben estar "de acuerdo con la misma [Constitución]"; y se sustituyó al Congreso de la Unión en materia de aprobación para dejar dicha labor únicamente al Senado de la República, CARPIZO, Jorge. La interpretación del artículo 133 constitucional. Boletín Mexicano de Derecho Comparado, Nueva Serie, año II, n. 4, Enero-Abril, 1969, pp. 7-8.

15 SCJN. La jerarquía normativa de los tratados internacionales en el derecho mexicano. México: Suprema Corte de Justicia de la Nación, 2008. p. 50-51.

16 El régimen que regula los tratados internacionales en México se deriva de los artículos 15, 18, 76 (I), 89 (X), $94\left(\S 8^{\circ}\right), 104,105$ (I-II), 107 (VIII), 117 (I) y 133 de la Constitución, que faculta al Presidente para celebrarlosmodificarlos, denunciarlos, suspenderlos, terminarlos o enmendarlos-y al Senado de aprobarlos.

17 SCJN. La jerarquía normativa de los tratados internacionales en el derecho mexicano. México: Suprema Corte de Justicia de la Nación, 2008, p. 58.
} 
orden cuando estén en oposición; y la examinación y control de constitucionalidad-y convencionalidad- - ${ }^{18}$ Así, la falta de claridad en el artículo 133 ha generado una copiosa práctica jurisprudencial por parte de los interpretes constitucionales en México. Los tribunales federales, han interpretado la manera en que los tratados internacionales, en general, se incorporaran al derecho interno, y cuál es su papel dentro del marco jurídico mexicano. Sin embargo, como lo veremos, estos criterios han sido cambiantes y confusos, y parecen insuficientes frente a la nueva realidad globalizada.

\subsection{Los derechos humanos en el marco jurídico vigente}

En 2011 México aprobó una reforma al artículo primero de la Constitución en donde otorga rango constitucional a todos los derechos humanos protegidos por tratados internacionales. ${ }^{19}$ Esta reforma es uno de los cambios más importantes que la legislación mexicana ha sufrido para reflejar el contexto globalizado de los derechos humanos. La reforma incorporó el término derechos humanos-abonando a la tradicional institución de las 'garantías individuales' - y reconoció que éstos deberán interpretarse de conformidad con la Constitución y los tratados internacionales, favoreciendo la protección más amplia a las personas, es decir reconoce como constitucional el principio pro persona. ${ }^{20}$ La reforma de 2011, se inserta, además, en una serie de reformas que van adoptando una óptica más favorable a los derechos humanos y parecen flexibilizar el sistema jurídico mexicano.

\subsubsection{Sistema de justicia penal acusatorio}

Algunos estados iniciaron, a partir del 2004, una transición hacia un sistema de justicia penal oral acusatorio, que contribuyó a una reforma a nivel nacional en 2008. ${ }^{21}$ El cambio buscaba reducir las ineficiencias del sistema tradicional, mediante la introducción de nuevos procedimientos y el fortalecimiento de los derechos tanto de las víctimas como de los inculpados. De tal forma, el sistema de justicia penal acusatorio replanteó el esquema tradicional de la justicia penal, dotándole de una cara más

\footnotetext{
18 CARPIZO, Jorge. La interpretación del artículo 133 constitucional. Boletín Mexicano de Derecho Comparado, Nueva Serie, año II, n. 4, ene./abr., 1969, p. 4.

19 Decreto por el que se modifica la denominación del Capítulo I del Título Primero y reforma diversos artículos de la Constitución Política de los Estados Unidos Mexicanos. Diario Oficial de la Federación, Tomo DCXCIII, n. 8, p. 2, 10 de junio 2011.

20 Decreto por el que se modifica la denominación del Capítulo I del Título Primero y reforma diversos artículos de la Constitución Política de los Estados Unidos Mexicanos. Diario Oficial de la Federación, Tomo DCXCIII, n. 8, p. 2, 10 de junio 2011.

21 RODRÍGUEZ FERREIRA, Octavio. El nuevo sistema penal acusatorio en México. In: OCTAVIO RODRÍGUEZ FERREIRA;SHIRK, David A. (Ed.). La reforma al sistema de justicia penal en México. San Diego: Justice in Mexico, University of San Diego, 2013. cap. 2.
} 
garantista, con una apuesta a la rapidez, eficiencia y transparencia de los procesos penales, y a la profesionalización de los operadores del sistema. ${ }^{22}$

El sistema acusatorio introdujo procesos orales, contenciosos y púbicos; el establecimiento de mecanismos alternativos para la solución de controversias; mayor énfasis en los derechos del acusado-presunción de inocencia, debido proceso y defensa-; garantías para la imparcialidad del juzgador y el equilibrio entre las facultades y poderes de las partes, entre muchos otros elementos. Todo lo anterior, con el objetivo general de lograr un balance entre la autoridad del Estado y los derechos de los ciudadanos. $^{23}$

\subsubsection{Efectos 'erga omnes' del amparo}

Otra reforma constitucional en 2011 estableció que todos los derechos humanos contenidos en los tratados internacionales, podían ser invocados en juicio de amparo. ${ }^{24}$ Dicha reforma también anuló la llamada "fórmula Otero" o principio de relatividad de las sentencias, que contemplaba que la protección otorgada por las sentencias de amparo sólo surtía efectos para los quejosos en el juicio. ${ }^{25}$ La declaratoria de inconstitucionalidad que se hiciere en sentencia de amparo, entonces, debía surtir efectos no sólo para los quejosos, sino para todo aquel que se encontrare dentro de la hipótesis normativa, aún sin ser parte en el juicio respectivo. ${ }^{26}$ De tal suerte, las sentencias de amparo que declaren la inconstitucionalidad de una ley pueden tener efectos generales, es decir su protección será erga omnes, lo que significa que será en beneficio de todos los ciudadanos.

22 RODRÍGUEZ FERREIRA, Octavio. El nuevo sistema penal acusatorio en México. In: OCTAVIO RODRÍGUEZ FERREIRA;SHIRK, David A. (Ed.). La reforma al sistema de justicia penal en México. San Diego: Justice in Mexico, University of San Diego, 2013. cap. 2.

23 SHIRK, David. Criminal Justice Reform in Mexico: An Overview. Mexican Law Review, vol. 3, n. 2, p. 189-228, 2011, passim; SHIRK, David A. Reforma de la Justicia Penal en México. In: RODRÍGUEZ FERREIRA, Octavio; SHIRK, David (Ed.). La reforma al sistema de justicia penal en México. San Diego: Justice in Mexico, University of San Diego, 2013, p. 11.

24 El concepto de interés legítimo representa la facultad de las personas que no son titulares de un derecho individual, pero que tienen un interés en la violación de cualquier derecho vulnerado por un acto de autoridad, a solicitar la protección del amparo, es decir, reconoce la legitimidad de cualquier ciudadano de solicitar la protección federal en contra de la legalidad de determinados actos de autoridad, a pesar de carecer de un derecho subjetivo, siempre y cuando se demuestre un interés suficiente. Decreto por el que se reforman, adicionan y derogan diversas disposiciones de los artículos 94, 103, 104 y 107 de la Constitución Política de los Estados Unidos Mexicanos. Diario Oficial de la Federación, Tomo DCXCIII, n. 4, p. 2, 6 de junio 2011.

25 La fórmula desarrollada por Mariano Otero se entiende como principio de petición de la parte agraviada, con protección limitada al caso especial, y sin ninguna declaración general, TENA RAMÍREZ, Felipe. Derecho Constitucional Mexicano. 32. ed. México: Porrúa, 1998, passim.

26 Decreto por el que se reforman, adicionan y derogan diversas disposiciones de los artículos 94, 103, 104 y 107 de la Constitución Política de los Estados Unidos Mexicanos. Diario Oficial de la Federación, Tomo DCXCIII, n. 4, p. 2, 6 de junio 2011. 
Este nuevo contexto más garantistas y favorable hacia los derechos humanos modificó el esquema en el que el derecho internacional ha sido concebido e interpretado dentro del marco jurídico mexicano, y, obligó a una revisión de la supremacía constitucional y de la jerarquía normativa. Sin embargo, esto no necesariamente vino a cambiar por completo la interpretación tradicional de dichos principios, ni tampoco a restructurar la forma en como se reciben e interactúan las normas internacionales en el derecho interno.

\section{SUPREMACÍA CONSTITUCIONAL Y LA JERARQUÍA NORMATIVA EN LA HISTORIA JURISPRUDENCIAL DE MÉXICO}

La supremacía constitucional ha sido un elemento fundamental en la tradición legislativa de México, y ha estado presente, de alguna u otra forma, en todas las leyes supremas del país en su historia independiente. De la misma forma, ha sido, también, un tema central y recurrente en la historia jurisprudencial del país, al menos a partir del siglo XX. En este apartado presentaré una serie de etapas jurisprudenciales respecto a la interpretación de la supremacía constitucional y la jerarquía normativa en el contexto de su interacción con normas de derecho internacional.

\subsection{La narrativa tradicional y originalista}

Siguiendo la consolidación institucional de México—después de los movimientos revolucionarios de principios del siglo XX_-, se gestó una primera etapa de interpretaciones jurisprudenciales que, de alguna forma, acogían las narrativas más tradicionales de la supremacía de la constitución, y de la jerarquía normativa.

Uno de los más tempranos pronunciamientos de los que se tenga noticia, en materia de tratados internacionales con relación al artículo 133 de la constitución, ocurrió en 1928, en el que estipulaba la "fuerza de ley" de los tratados. Este pronunciamiento demuestra un criterio que pensaba la ley interna como única, sin concebir, obviamente, la importancia que tienen los tratados en la actualidad. ${ }^{27}$

La primera decisión concreta sobre la jerarquía normativa en México fue una tesis aislada de 1948, de la Primera Sala de la Suprema Corte de Justicia de la Nación [referida también como SCJN] que estipula que "todo tratado o convenio celebrado por el Presidente de la República, así esté aprobado por el Senado, pero que contradiga o esté en oposición con los preceptos de la Constitución, en los puntos o actos en que esto acontezca, no debe tener eficacia jurídica". ${ }^{28}$ Esta tésis indirectamente determina la jerarquía de los ordenamientos jurídicos reafirmando el principio de supremacía

\footnotetext{
27 SCJN. Tratados. [TA]; 5a. Época; Pleno; S.J.F., Tomo XXII, 1928.

28 SCJN. Tratados Internacionales, Validéz de los. [TA] 5a. Época; 1a. Sala, S.J.F., Tomo XCVI, 1948.
} 
constitucional. En 1953, la Suprema Corte reiteró su criterio de 1948, en una tesis que reafrima que los tratados que contradijeran o se opusieran a la Constitución no debían tener eficacia jurídica. ${ }^{29}$

En esta primera etapa jurisprudencial, las interpretaciones coincidian en la falta de eficacia jurídica de un tratado si contradecía o se oponía a la Constitución, aunque no se restó su obligatoriedad, y se aclaró su "fuerza de ley".30 Esta etapa representa la visión de la Constitución en la cúspide del marco normativo, seguida por sus leyes reglamentarias. Por debajo, se ubicaban lo tratados, que hasta entonces no tenían gran influencia directa en el derecho interno, y mucho menos podía pensarse que tuvieran fuerza mayor que las otras leyes supremas. Este criterio reinó durante gran parte del siglo XX.

\subsection{Una incipiente apertura}

En las últimas décadas del siglo XX algunos criterios seguían argumentando que no podía establecerse que los tratados fueran de mayor obligación que las leyes federales, pero se empezaba a generar un cambio.

Una tesis de un Tribunal Colegiado de Circuito [también referido como TCC] en 1981 refiere que lo estipulado por el artículo 133 constitucional establece el principio de la supremacía respecto de las constituciones y leyes estatales, pero no establece "la aplicación preferente de las disposiciones contenidas en los tratados respecto de lo dispuesto por las leyes [federales]". De tal forma, esta es "una regla de conflicto a que deben sujetarse las autoridades mexicanas, pero [...] no puede establecerse que los tratados sean de mayor obligación [...] que las leyes del Congreso".31 Nuevamente se confirma que los tratados son parte del derecho interno, se reconoce su fuerza obligatoria, pero no se les otorga un rango superior al de las leyes federales.

Sin embargo, este criterio se acompañó de otro del mismo TCC, también de 1981, que reconoce, en los mismos términos, que no puede establecerse que los tratados sean de mayor obligación que las leyes del Congreso ya que el artículo 133 no establece preferencia alguna entre ellos, ni afirma supremacía entre el derecho internacional sobre el interno, sino que reconoce que el primero es parte del segundo, "ya que si bien reconoce la fuerza obligatoria de los tratados, no da a éstos un rango superior a

\footnotetext{
29 SCJN. Tratados, Validez de los. [TA]; 5a. Época; 1a. Sala; S.J.F, Tomo CXX, 1953.

30 SCJN. Tratados. [TA]; 5a. Época; Pleno; S.J.F., Tomo XXII, 1928. Además de esta tesis de 1928, el criterio se repitió en 1950 en el mismo sentido. SCJN. Tratados, fuerza de los. Las estipulaciones contenidas en los tratados celebrados con las potencias extranjeras, tienen fuerza de ley para los habitantes del país. 5a. Época, 2a. Sala; S.J.F., Tomo CIV, p. 2243, 26 de junio 1950.

31 SCJN. Tratados internacionales. El articulo 133 constitucional, última parte, no establece su observancia preferente sobre las leyes del Congreso de la Unión emanadas de la Constitución Federal. [TA]; 7a. Época; T.C.C.; S.J.F., Volumen 151-156, Sexta Parte, 1981.
} 
las leyes del Congreso de la Unión emanadas de esa Constitución, sino que el rango que les confiere a unos y otras es el mismo".32

De tal forma se empezaba a concebir una complementariedad entre los tratados y las leyes generales, en una época de enfrentamiento de las instituciones nacionales frente la inminente globalización, y ante la presión de la clase política para adaptar el sistema jurídico a la apertura de los mercados internacionales y a los tratados de libre comercio.

La Suprema Corte, confirmó el criterio de que los tratados y las leyes federales tenían la misma jerarquía que las leyes federales en 1992. Esta tesis razona que las leyes y los tratados tienen una posición "inmediatamente inferior a la Constitución en la jerarquía de las normas en el orden jurídico mexicano", y que, si bien tienen entre ellos la misma jerarquía, "el tratado internacional no puede ser criterio para determinar la constitucionalidad de una ley ni viceversa".33

La postura de la Corte confirma un cambio discreto que concibe una similar jerarquía de los tratados y las leyes generales, sin otorgar superioridad jerárquica de unos sobre otros, ni de cualquiera de ellos sobre la Constitución.

\subsection{La consolidación global del derecho internacional}

Tradicionalmente se considera que la etapa de la posguerra y la instauración de las Naciones Unidas representó la consolidación del derecho internacional y de los derechos humanos. Sin embargo, muchas veces se olvida que esa consolidación, y el triunfo del discurso iushumanista se 'consumó' con la caída del muro de Berlín, como símbolo de la desintegración del mundo bipolar de la guerra fría y el colapso del bloque comunista. En efecto, 1989 representó el triunfo y expansión por el mundo del discurso

\footnotetext{
32 SCJN. Tratados internacionales. El articulo 133 constitucional, última parte, no establece su observancia preferente sobre las leyes del Congreso de la Unión emanadas de la Constitución Federal. [TA]; 7a. Época; T.C.C.; S.J.F., Volumen 151-156, Sexta Parte, 1981. La misma postura se confirmaría nuevamente en 1987. SCJN. Estupefacientes o Psicotrópicos considerados así en los convenios o tratados internacionales. [TA]; 7a. Época; T.C.C.; S.J.F., Volumen 217-228, Sexta Parte, 1987. Es pertinente subrayar la postura unitaria claramente monista adoptada por el juzgador mexicano que coincide, en gran medida, con la interpretación kelseniana, que concibe a las normas de derecho internacional como incompletas, y que requieren de implementación mediante normas de derecho interno. KELSEN, Hans. Principles of International Law. 2nd ed. New York: Holt, Rinehart and Winston, 1966. p. 553. Al respecto, es relevante recordar, también, que, aunque el Kelsen de la última época estaba claramente inclinado a la supremacía de los derechos humanos-y del derecho internacional-, su teoría monista claramente asume la posibilidad de la aplicación primaria del derecho interno con una base política. CRAWFORD, James. Brownlie's Principles of Public International Law. 8 ed. Oxford: Oxford University Press, 2012, p.49-50.

33 SCJN. Leyes federales y tratados internacionales. Tienen la misma jerarquía normativa. [TA]; 8a. Época; Pleno; Gaceta S.J.F., Núm. 60, Diciembre de 1992, n. P. C/92, 1992.
} 
global de los derechos humanos, indudablemente apegado a la consolidación de las democracias liberales. ${ }^{34}$

Frente a esta tendencia global, a finales de los años noventa la Suprema Corte dio un giro significativo a la luz de sus obligaciones frente al derecho internacional, ${ }^{35} \mathrm{y}$ abandonó su criterio de 1992, respecto a la igual jerarquía entre leyes federales y tratados, para sostener, por primera vez, la jerarquía superior de los tratados frente al derecho federal, pero "en un segundo plano inmediatamente debajo de la Constitución".36

Ya iniciado el siglo XXI este criterio se siguió manteniendo. Ejemplo de ello es la tesis de 2004, en donde se expresa que los tratados internacionales reglamentan y amplían los derechos fundamentales tutelados por la Constitución, y que deben aplicarse sobre las leyes federales que no lo hacen, sobre todo cuando sus presupuestos se complementan con otras leyes federales. ${ }^{37}$

Al año siguiente una tesis de un TCC consideró que "...es factible que una disposición ordinaria pueda ser declarada contraria a un tratado internacional [...], si sus postulados contravienen a los contenidos sustanciales del instrumento internacional,

34 DOUZINAS, Costas. The End of Human Rights. Oxford: Hart Publishing, 2000, passim. Según Gearty, los dos grandes resultados que siguieron a 1945 fue la internacionalización de los derechos humanos, y, basados en ellos, la consolidación de la democracia liberal, principalmente en los países derrotados en la guerra. De la misma forma que en 1945, los acontecimientos ocurridos a partir de 1989 produjeron un proceso a gran escala de "construcción de naciones" basados en los grandes principios de democracia y derechos humanos. GEARTY, Conor. Spoils for which victor? Human rights within the democratic state. In: GEARTY, Conor; DOUZINAS, Costas (Ed.). The Cambridge Companion to Human Rights Law. New York: Cambridge University Press, 2012. p. 214.

35 Principalmente, entiéndase la obligación de que ninguna parte firmante de un tratado podrá invocar su derecho interno para justificar su incumplimiento. Vienna Convention on the Law of Treaties. 1155 U.N.T.S. 331. Vienna: United Nations. 1969.

36 Bajo esta nueva interpretación, la Suprema Corte, expresamente asume que, si bien no existe duda respecto a la supremacía de la Constitución-ya que las leyes federales deben emanar de la misma y ser aprobadas por el Congreso, y que los tratados deben estar de acuerdo con ella-, los tratados se encuentran en un segundo plano inmediatamente por debajo de la Constitución y por encima del derecho federal y el local, ya que "Ios compromisos internacionales son asumidos por el Estado mexicano en su conjunto y comprometen a todas sus autoridades frente a la comunidad internacional; por ello se explica que el Constituyente haya facultado al presidente de la República a suscribir los tratados internacionales en su calidad de jefe de Estado y, de la misma manera, el Senado interviene como representante de la voluntad de las entidades federativas y, por medio de su ratificación, obliga a sus autoridades". La Corte añade que en materia de tratados no existe limitación competencial entre órdenes de gobierno en tanto que pueden "obligar al Estado mexicano en cualquier materia, independientemente de que para otros efectos ésta sea competencia de las entidades federativas". Por lo tanto, ubica, en un tercer plano, al derecho federal y al local en una misma jerarquía, en tanto que regulan diferentes competencias. SCJN. Tratados internacionales. Se ubican jerárquicamente por encima de las leyes federales y en un segundo plano respecto de la Constitución Federal. [TA]; 9a. Época; Pleno; S.J.F. y su Gaceta, Tomo X, Noviembre de 1999, n. P. LXXVII/99, 1999. Es pertinente recordar la decisión de la Suprema Corte de Estados Unidos en el caso Medellin v. Texas-producto del litigio entre México y Estados Unidos ante la Corte Internacional de Justicia, conocido como Avena-en donde, contrariamente, se establece que incluso si un tratado internacional puede constituir un compromiso internacional, no es vinculante para el derecho interno a menos que el Congreso haya promulgado algún estatuto para implementarlo, o bien que el tratado sea "autoejecutable". Medellín v. Texas. United States Reports, 552 U.S. 491, 2008.

37 SCJN. Tratados internacionales. Su aplicación cuando amplían y reglamentan derechos fundamentales. [TA]; 9a. Época; T.C.C.; S.J.F. y su Gaceta, Tomo XX, Septiembre de 2004, n. I.4o.A.440 A., 2004. 
cuya jerarquía se ubica en un plano superior a la legislación ordinaria". ${ }^{38}$ Dicha tesis vuelve a confirmar el criterio de la superioridad jerárquica de los tratados sobre las leyes federales y más aún declara inconstitucional una norma por su inconsistencia con un instrumento internacional.

Este criterio, seguido por diversos tribunales, es refrendado por el Pleno de la Suprema Corte en 2007, con una tesis que afirma que es posible "identificar la existencia de un orden jurídico superior, de carácter nacional, integrado por la Constitución Federal, los tratados internacionales y las leyes generales" y que, a través de la interpretación, es posible concluir que los tratados se ubican jerárquicamente abajo de la Constitución y por encima de las leyes federales y locales, ya que el Estado al momento de suscribirlos, de acuerdo con la Convención de Viena Sobre el Derecho de los Tratados y "además atendiendo al principio fundamental de derecho internacional consuetudinario 'pacta sunt servanda', contrae libremente obligaciones [...] que no pueden ser desconocidas invocando normas de derecho interno y cuyo incumplimiento supone [...] una responsabilidad de carácter internacional".39

La tendencia jurisprudencial materializada en los últimos criterios expuestos comienza a mostrar una apertura a la normativa internacional, pero al mismo tiempo evidencia una creciente problemática: el razonamiento jurisprudencial con relación al texto del artículo 133 constitucional, hace referencia genérica a los tratados internacionales, por lo que, una mayor flexibilidad ante los tratados de derechos humanos podría ser igualmente aplicable aquellos de carácter económico e incluso los meramente políticos.

\subsection{Hacia un cambio de paradigma}

Frente al 'triunfo' de los derechos humanos internacionales, ${ }^{40}$ el principio tradicional de supremacía constitucional comenzó a cuestionarse a nivel mundial. De la misma forma, nuevos criterios jurisprudenciales sostenían que los tratados de derechos humanos, exclusivamente, debían ubicarse a nivel de la Constitución cuando existiera

38 SCJN. Tratados Internacionales. La Norma programática prevista en la fracción III, inciso b) del artículo 128 del Código Federal de Procedimientos Penales, es contraria al artículo 8.2 de la Convención Americana de Derechos Humanos. [TA]; 9a. Época; T.C.C.; S.J.F. y su Gaceta, Tomo XXI, Mayo de 2005, n. II.10.P.137 P, 2005.

39 SCJN. Tratados internacionales. Son parte integrante de la ley suprema de la Unión y se ubican jerárquicamente por encima de las leyes generales, federales y locales. Interpretación del artículo 133 constitucional. [TA]; 9a. Época; Pleno; S.J.F. y su Gaceta, Tomo XXV, , n. P. IX/2007, Abril 2007.; Otros criterios refieren a la supremacía de la Constitución, pero sin determinar exactamente la jerarquía de los tratados: SCJN. Supremacía constitucional y ley suprema de la Unión. Interpretación del artículo 133 constitucional. [TA]; 9a. Época; Pleno; S.J.F. y su Gaceta, Tomo XXV, Abril de 2007; n. P. VIII/2007, p. Pág. 6, 2007; y SCJN. Derechos humanos, Los tratados internacionales suscritos por México sobre los. Es posible invocarlos en el juicio de amparo al analizar las violaciones a las garantías individuales que impliquen la de aquéllos. [TA]; 9a. Época; T.C.C.; S.J.F. y su Gaceta, Tomo XXVIII, Agosto de 2008, n. I.7o.C.46 K, 2010.

40 DOUZINAS, Costas. The End of Human Rights. Oxford: Hart Publishing, 2000, passim. 
un conflicto normativo, ya que los tratados debían concebirse como una extensión de lo previsto por la Constitución. ${ }^{41}$

En este sentido, en el amparo directo en revisión 908/2006, el ministro de la Suprema Corte José Ramón Cossío Díaz, en voto concurrente, expresó:

Al ser los tratados de derechos fundamentales [...] instrumentos jurídicos que buscan garantizar el goce de derechos y libertades del ser humano, difícilmente podrían oponerse a la intención que plasmó el Constituyente y al texto mismo de la Constitución, aun en aquellos casos que la norma suprema establece restricciones que pudieran considerarse insuperables, pues en estos casos, tomando en cuenta los derechos que protegen, esas restricciones deben ser interpretadas de manera progresiva con los tiempos y las condiciones de vida actuales. ${ }^{42}$

La postura expresada por Cossío tuvo acogida, en mayor o menor medida, en la interpretación jurisprudencial a finales de la primera década del siglo XXI como veremos posteriormente.

\subsubsection{Control constitucional y convencional a partir del caso Radilla}

El cambio más radical en la interpretación jurisprudencial mexicana en materia de derechos humanos es, quizá, el que generó la sentencia condenatoria de la Corte Interamericana de Derechos Humanos [en adelante Corte IDH] en el año de 2009 en el caso Radilla Pacheco vs. México, ${ }^{43}$ y en el análisis que hizo la Suprema Corte para examinar y orientar al Estado a la luz de las obligaciones producto de dicha sentencia. ${ }^{44}$

La resolución de la Corte IDH en el Caso Radilla determinó que el Estado mexicano era responsable de la violación de los derechos a la libertad, a la integridad, al reconocimiento de la personalidad jurídica, a la vida, a las garantías judiciales y a la protección judicial en perjuicio de Rosendo Radilla Pacheco y su familia. ${ }^{45}$ La Corte IDH obligó a México entre otras cosas a adoptar reformas legislativas para compatibilizar la legislación penal y militar con los instrumentos jurídicos internacionales. ${ }^{46}$

41 Amparo Directo 1060/2008. 9a. Época; T.C.C.; S.J.F., Tomo XXXI, p. 2079, Mayo 2010.

42 Amparo Directo en Revisión 908/2006. 9a Época. 1a Sala. S.J.F. y su Gaceta, 18 de abril 2007.

43 Radilla Pacheco vs. México. Corte IDH. Serie C, 215. 2010. El caso analizó la participación de militares en la desaparición forzada de Rosendo Radilla en 1974.

44 Varios 912/2010. Suprema Corte de Justicia de la Nación. México, 2011.

45 La Corte IDH además determinó que México incumplió su deber de adoptar disposiciones de derecho interno con relación a disposiciones aplicables del sistema interamericano respecto de la tipificación del delito de desaparición forzada. Radilla Pacheco vs. México. Corte IDH. Serie C, 215. 2010.

46 Al respecto, debe citarse el contenido del artículo 2 de la Convención Americana que establece que los Estados Partes se comprometen a adoptar, con arreglo a sus procedimientos constitucionales y a las disposiciones de la Convención, las medidas legislativas necesarias para hacer efectivos los derechos y libertades ahí 
En acato a lo dispuesto por la Corte IDH en el caso Radilla, la Suprema Corte tuvo que analizar, por primera vez, la autoridad de dicho tribunal internacional para obligar a México a cumplir con sus decisiones. El 14 de julio de 2011, después de un largo debate en torno al expediente 912/2010, el Pleno de la Suprema Corte, por unanimidad de once votos, reconoció que los fallos condenatorios de la Corte IDH son vinculantes para México, así como que sus criterios interpretativos son orientadores para el los jueces. ${ }^{47}$

La resolución de la Suprema Corte, además, analizó otros temas importantes, como el control difuso de constitucionalidad, figura rechazada por décadas en el derecho mexicano, ${ }^{48}$ que permite a todos los jueces, tanto federales como locales, interpretar directamente la Constitución y los tratados internacionales en los casos que se les presenten. La Suprema Corte determinó que se debía ejercer un control de convencionalidad ex officio entre las normas internas y la Convención Americana, y también se determinó la capacidad de todos los jueces mexicanos-federales y locales-para interpretar y aplicar las normas constitucionales y convencionales de manera directa, es decir, realizar control difuso de constitucionalidad y de convencionalidad. ${ }^{49}$

En su fallo, la Suprema Corte no sólo determinó que la jurisprudencia de la Corte IDH es vinculante para los jueces mexicanos, sino que, además, no se requiere, para tal efecto, que México haya sido parte en el litigio, siempre y cuando dicha provisión sea más favorable para la persona, es decir que los jueces mexicanos deben atender todas las resoluciones de la Corte IDH, y no sólo aquellas en las que México haya sido parte, aplicando el principio pro persona. ${ }^{50}$ Lo anterior dio lugar a la tesis: "Jurisprudencia emitida por la Corte Interamericana de Derechos Humanos. Es vinculante para los jueces mexicanos siempre que sea más favorable a la persona". ${ }^{51}$

\subsubsection{Igualdad jerárquica de los tratados de derechos humanos y de la Constitución}

Otro cambio fundamental vino con un par de tesis que de alguna forma confirman y adoptan el criterio postulado por Cossío en el Amparo 908/2006 con relación a que los tratados internacionales en materia de derechos humanos deben ubicarse al mismo nivel de la Constitución.

consagrados. Convención Americana de Derechos Humanos (Pacto de San José) San José: Organización de los Estados Americanos. 1969.

47 Varios 912/2010. Suprema Corte de Justicia de la Nación. México, 2011.

48 TENA RAMÍREZ, Felipe. Derecho Constitucional Mexicano. 32. ed. México: Porrúa, 1998, passsim.

49 Varios 912/2010. Suprema Corte de Justicia de la Nación. México, 2011.

50 Varios 912/2010. Suprema Corte de Justicia de la Nación. México, 2011.

51 SCJN. Jurisprudencia emitida por la Corte Interamericana de Derechos Humanos. Es vinculante para los jueces mexicanos siempre que sea más favorable a la persona. [J]; 10a. Época; Pleno; Gaceta S.J.F.; Libro 5, Tomo I, Abril de 2007; n. P./J. 21/2014 (10a.). 2014. 
Una tesis aislada de mayo de 2010 consideró que cuando existieran conflictos en relación con derechos humanos, los tratados debían ubicarse a nivel constitucional, pues debían considerarse como una extensión de lo previsto en la Constitución. Aún más, establece que las autoridades deben respetar dichos tratados, por lo que "bajo ninguna circunstancia pueden ser ignorados por ellos al actuar de acuerdo a su ámbito competencial".52 Además, el mismo tribunal emitió otra tesis confirmando la capacidad de los jueces de ejercer, tanto un control de constitucionalidad, como uno de convencionalidad, en los casos en que fuera aplicable. ${ }^{53}$

Estas tesis, entonces, establecen tres criterios innovadores: a) que ante un conflicto sobre derechos humanos, los tratados deben ubicarse al mismo nivel de la Constitución; b) que las autoridades mexicanas están vinculadas por la jurisprudencia de tribunales internacionales para la interpretación y cumplimiento de derechos humanos; y c) la aplicabilidad del principio pro persona, que implica acudir a la norma más amplia o a la interpretación más extensiva tratándose de protección de derechos, y, de manera opuesta, a la norma o interpretación más restringida, tratándose de límites a su ejercicio. ${ }^{54}$ Una de estas tesis especificó lo siguiente:

Los tratados o convenciones [...] relativos a derechos humanos, deben ubicarse a nivel de la Constitución [...] porque dichos instrumentos internacionales se conciben como una extensión de lo previsto en esa Ley Fundamental respecto a los derechos humanos, en tanto que constituyen la razón y el objeto de las instituciones. Por lo que los principios que conforman el derecho subjetivo público, deben adecuarse a las diversas finalidades de los medios de defensa que prevé la propia Constitución y de acuerdo con su artículo 133 las autoridades mexicanas deben respetarlos, por lo que bajo ninguna circunstancia pueden ser ignorados por ellos al actuar de acuerdo a su ámbito competencial. ${ }^{55}$

\subsection{Ad Contradictio: de vuelta al statu quo ante}

Simultáneamente al anterior criterio, se emitieron otros que no sólo reivindicaban la posición más consolidada de la jerarquía normativa, sino que contradecían su

52 SCJN. Tratados internacionales. Cuando los conflictos se susciten en relación con derechos humanos, deben ubicarse a nivel de la Constitución. [TA]; 9a. Época; T.C.C.; S.J.F. y su Gaceta, Tomo XXXI n. XI.10.A.T.45 K., 2010. Como se verá posteriormente, el criterio adoptado en esta tesis se abandonó por contradicción, y, en su lugar, se emitieron las tesis jurisprudenciales P./J. 20/2014 (10a.) y P./J. 21/2014 (10a.).

53 SCJN. Control de convencionalidad en sede interna. Los tribunales mexicanos están obligados a ejercerlo. [TA]; 9a. Época; T.C.C.; S.J.F. y su Gaceta, Tomo XXXI n. XI.10.A.T.47 K, p. Pág. 1932, 2010.

54 Contradicción de Tesis 293/2011. SCJN. Gaceta del Semanario Judicial de la Federación, Libro 5, Tomo I, 2013

55 SCJN. Tratados internacionales. Cuando los conflictos se susciten en relación con derechos humanos, deben ubicarse a nivel de la Constitución. [TA]; 9a. Época; T.C.C.; S.J.F. y su Gaceta, Tomo XXXI n. XI.10.A.T.45 K., 2010. 
interpretación. Este otro criterio argumentó que, en efecto, los tratados internacionales podían ser invocados para analizar casos de violaciones a los derechos humanos, toda vez que son parte de un sistema jurídico con base en el principio de que "las leyes se hicieron para servir al hombre, por lo que es posible llevar a cabo todas las acciones necesarias para restituir o resarcir a las personas en el goce de sus derechos". Sin embargo, confirmó la posición dominante de infraconstitucionalidad de los tratados internacionales. ${ }^{56}$ La tesis establece lo siguiente:

Por su parte, la Suprema Corte de Justicia de la Nación ubicó a los tratados internacionales por encima de las leyes federales y por debajo de la Constitución [...] De ahí que si en el amparo es posible conocer de actos o leyes violatorios de garantías individuales establecidas constitucionalmente, también pueden analizarse los actos y leyes contrarios a los tratados internacionales [...] por formar parte de la Ley Suprema de toda la Unión en el nivel que los ubicó la Corte. Por lo tanto, pueden ser invocados al resolver sobre la violación de garantías individuales que involucren la de los derechos humanos reconocidos en los tratados internacionales suscritos por México. ${ }^{57}$

Este criterio confirmó que los tratados internacionales podían ser invocados en casos de violaciones a derechos humanos pero afirmó que su rango seguía siendo infraconstitucional. Al mismo tiempo reconoció, por un lado, que era obligatoria la aplicación del principio pro persona, y, por otro, que las decisiones de Corte IDH servían como criterios para la interpretación de derechos humanos. ${ }^{58}$

\subsubsection{Configuración de una 'nueva' narrativa: la C.T. 293/11}

En efecto, los anteriores criterios resultaron divergentes e incluso opuestos con relación a varios puntos jurídicos: a) la posición jerárquica de los tratados en materia de derechos humanos con relación a la Constitución; b) el carácter de la jurisprudencia emitida por la Corte IDH; y c) el control de convencionalidad. ${ }^{59}$ Esto llevó la Suprema Corte a dirimir dicha contradicción y, además, armonizar el artículo primero con el artículo 133 constitucional. Aún cuando ambos criterios contradictorios ocurrieron bajo un marco constitucional diferente, previo a la reforma de 2011, la Suprema Corte estimó analizar el caso bajo el marco vigente posterior a la reforma, debido a que, en

56 Contradicción de Tesis 293/2011. SCJN. Gaceta del Semanario Judicial de la Federación, Libro 5, Tomo I, 2013.

57 SCJN. Derechos humanos, Los tratados internacionales suscritos por México sobre los. Es posible invocarlos en el juicio de amparo al analizar las violaciones a las garantías individuales que impliquen la de aquéllos. [TA]; 9a. Época; T.C.C.; S.J.F. y su Gaceta, Tomo XXVIII, Agosto de 2008, n. I.7o.C.46 K, p. Pág. 1083, 2008.

58 Contradicción de Tesis 293/2011. SCJN. Gaceta del Semanario Judicial de la Federación, Libro 5, Tomo I, 2013.

59 Contradicción de Tesis 293/2011. SCJN. Gaceta del Semanario Judicial de la Federación, Libro 5, Tomo I, 2013. 
la perspectiva de la Corte, los asuntos analizados se encontraban estrechamente vinculados a dichos cambios. ${ }^{60}$

La Suprema Corte determinó que, en efecto, existía contradicción entre los mencionados criterios, toda vez que, por un lado, se sostuvo que los tratados internacionales se encuentran por debajo de la Constitución, ${ }^{61}$ mientras que, por otro, se alegó que, ante un conflicto en materia de derechos humanos, los tratados debían ubicarse al mismo nivel de la norma fundamental. ${ }^{62}$

La C.T. 293/11, se enfocó, entonces, en resolver la contradicción relativa a la situación jerárquica de los tratados internacionales en materia de derechos humanos vis-á-vis la Constitución. Al, respecto, la Corte concluyó en su resolución del dos de septiembre de dos mil trece que las normas contenidas en tratados internacionales que reconocen derechos humanos tienen la misma fuerza normativa que las contenidas en la Constitución, pero que, cuando en la misma haya una restricción expresa al ejercicio de dichos derechos, se deberá estar a lo que indica el texto constitucional. ${ }^{63}$

En cuanto a los otros puntos identificados por la Corte, se determino que, ciertamente, un criterio había considerado a la jurisprudencia de la Corte IDH como criterio meramente orientador, mientras que otro le había otorgado un carácter obligatorio. El segundo punto resolutivo, adoptó el criterio de que la jurisprudencia emitida por la Corte IDH es vinculante para los jueces mexicanos siempre que sea más favorable a la persona. Con relación al tercer y último punto, toda vez que ambos tribunales

60 Contradicción de Tesis 293/2011. SCJN. Gaceta del Semanario Judicial de la Federación, Libro 5, Tomo I, 2013. Es pertinente mencionar aquí, que en el análisis que hace la Suprema Corte en la resolución 293/11 sobre las interpretaciones históricas acerca de la posición jerárquica de los tratados internacionales con respecto a la Constitución, no se citan varios de los criterios jurisprudenciales que he mencionado hasta ahora. En la resolución se identifica como primera tesis relevante en la materia aquella de 1992 de rubro "Leyes federales y tratados internacionales. Tienen la misma jerarquía normativa", y omite varias tesis relevantes previas.

61 SCJN. Derechos humanos, Los tratados internacionales suscritos por México sobre los. Es posible invocarlos en el juicio de amparo al analizar las violaciones a las garantías individuales que impliquen la de aquéllos. [TA]; 9a. Época; T.C.C.; S.J.F. y su Gaceta, Tomo XXVIII, Agosto de 2008, n. I.7o.C.46 K, p. Pág. 1083, 2008.

62 SCJN. Tratados internacionales. Cuando los conflictos se susciten en relación con derechos humanos, deben ubicarse a nivel de la Constitución. [TA]; 9a. Época; T.C.C.; S.J.F. y su Gaceta, Tomo XXXI n. XI.10.A.T.45 K. 2010.

63 Contradicción de Tesis 293/2011. SCJN. Gaceta del Semanario Judicial de la Federación, Libro 5, Tomo I, 2013. Si bien es cierto que el último proyecto de resolución planteado para el caso de la C.T. 293/11 no fue aceptado de manera unánime, este criterio se aprobó con una con mayoría de diez votos a favor y sólo un voto en contra, el del ministro Cossío, quien había expresado, en repetidas ocasiones durante los debates, que la Corte no podía considerarse por encima de los tratados de derechos humanos. Cossío votó en contra del proyecto argumentando que, este fallo particular, no establecía una regla general a seguir cuando hubiera un conflicto entre un tratado y la constitución, que permitiera a los jueces decidir el asunto sobre una base caso por caso. Antes bien, dicho punto aprobado por la Corte provocaría que cada vez que hubiera un conflicto entre un tratado y la constitución, el juez tendría que interpretar y decidir en consecuencia, alterando, así, el propósito original de las discusiones para crear una regla general sobre la jerarquía de los derechos humanos y el derecho internacional vis-á-vis el derecho interno. 
sostuvieron la pertinencia del control de convencionalidad, se determinó que no existía contraposición al respecto. ${ }^{64}$

\subsubsection{La narrativa de la "regularidad constitucional" y del "bloque de constitucionalidad"}

La resolución de la Suprema Corte en la C.T. 293/11 dio lugar a dos tesis jurisprudenciales. La primera, establece que "las normas de derechos humanos, independientemente de su fuente, no se relacionan en términos jerárquicos, entendiendo que, [...] cuando en la Constitución haya una restricción expresa al ejercicio de los derechos humanos, se deberá estar a lo que indica la norma constitucional".65

Esta tesis expresa que el contenido del principio de supremacía no ha cambiado, lo que "evolucionó" a raíz de las reformas de 2011 "es la configuración del conjunto de normas jurídicas respecto de las cuales puede predicarse dicha supremacía". Es decir, con los tratados se amplía el catálogo de derechos humanos previsto dentro de la Constitución, el que se considera como "parte del conjunto normativo que goza de esta supremacía constitucional", es decir se convierte en parte de la Constitución y por ende no le sustituye. ${ }^{66}$ Este concepto fue denominado bloque de constitucionalidad.

La segunda tesis, que desarrolla el llamado 'parámetro de regularidad constitucional', y que confirma la postura de supremacía constitucional frente a los tratados internacionales enfatiza que la "Leyes del Congreso de la Unión" a las que se refiere el artículo 133 corresponden a las leyes que inciden en "todos los órdenes jurídicos parciales que integran al Estado Mexicano" y no sólo las federales, ya que la emisión de todas ellas derivan de cláusulas constitucionales, de tal forma, el principio de supremacía constitucional "claramente se traduce" en que la Constitución, las leyes generales del Congreso y los tratados internacionales, constituyen dicha "Ley Suprema de la Unión", ya que conforman un "orden jurídico superior" en donde la Constitución "se ubica en la cúspide" $y$, por debajo de ella, cualquier otro ordenamiento. ${ }^{67}$

64 Contradicción de Tesis 293/2011. SCJN. Gaceta del Semanario Judicial de la Federación, Libro 5, Tomo I, 2013.

65 SCJN. Derechos humanos contenidos en la Constitución y en los tratados internacionales. Constituyen el parámetro de control de regularidad constitucional, pero cuando en la Constitución haya una restricción expresa al ejercicio de aquéllos, se debe estar a lo que establece el texto constitucional. [J]; 10a. Época; Pleno; Gaceta S.J.F., Libro 5, Tomo I , Abril de 2014, n. P./J. 20/2014 (10a.), 2014.

66 SCJN. Derechos humanos contenidos en la Constitución y en los tratados internacionales. Constituyen el parámetro de control de regularidad constitucional, pero cuando en la Constitución haya una restricción expresa al ejercicio de aquéllos, se debe estar a lo que establece el texto constitucional. [J]; 10a. Época; Pleno; Gaceta S.J.F., Libro 5, Tomo I, Abril de 2014, n. P./J. 20/2014 (10a.), 2014.

67 SCJN. Supremacía constitucional y ley suprema de la Unión. Interpretación del artículo 133 constitucional. [TA]; 9a. Época; Pleno; S.J.F. y su Gaceta, Tomo XXV, n. P. VIII/2007, Abril 2014. 


\subsubsection{La 'nueva' jerarquía normativa en México}

Hasta el momento he seguido una trayectoria mayormente lineal siguiendo los criterios jurisprudenciales de acuerdo a su temporalidad, e insertándolos en el marco conceptual. Pero aquí es necesario un breve paso atrás. Previo a la C.T. 293/11 hubo una tesis jurisprudencial, independiente a los criterios anteriormente citados, que interpreta la jerarquía normativa del artículo 133 a raíz de la reforma al artículo primero constitucional.

Esta tesis de 2012 de la segunda sala de la Suprema Corte enuncia que la reforma de 2011 no modifica el contenido del citado artículo 133 en cuanto a que categóricamente ordena que las limitaciones y restricciones al ejercicio de los derechos humanos sólo pueden establecerse en la Constitución, lo que es acorde con el principio de supremacía constitucional. ${ }^{68}$

Dicha tesis concluye que las leyes y los tratados internacionales se encuentran en un plano jerárquicamente inferior al de la Constitución, haciendo un razonamiento idéntico a aquel de $1999,{ }^{69}$ en cuanto a que, de la misma lectura del artículo, las leyes federales y los tratados deben emanar o estar de acuerdo, respectivamente, con la Constitución. En esta ocasión la Sala de la Corte agregó que, ya que otros preceptos constitucionales no fueron afectados, tanto el derecho interno como los tratados internacionales, pueden ser sometidos al control constitucional a través de la acción de inconstitucionalidad, la controversia constitucional y el juicio de amparo.

La tesis enfatizó que el artículo reformado reconoce "limitaciones y restricciones" al ejercicio de los derechos humanos sólo cuando estén establecidas en la Constitución y no en los tratados, "disposición que [también] resulta acorde con el principio de supremacía constitucional”. El razonamiento va más allá al afirmar que el principio de supremacía es también reconocido en el derecho internacional a través del artículo 46 de la Convención de Viena, ${ }^{70}$ al prever la posibilidad de aducir, como vicio en el consentimiento, la existencia de una violación manifiesta que afecte a una norma de importancia fundamental de su derecho interno. ${ }^{71}$ La Sala de la Corte refrendó, entonces,

\footnotetext{
68 SCJN. Supremacía constitucional. La reforma al artículo 1o de la Constitución Política de los Estados Unidos Mexicanos, de 10 de junio de 2011, respeta este principio. [TA]; 10a. Época; 2a. Sala; S.J.F. y su Gaceta, Libro XIII, Octubre de 2012, Tomo 3, n. 2a. LXXV/2012 (10a.). 2012.SCJN.

69 SCJN. Tratados internacionales. Se ubican jerárquicamente por encima de las leyes federales y en un segundo plano respecto de la Constitución Federal. [TA]; 9a. Época; Pleno; S.J.F. y su Gaceta,, Tomo X, Noviembre de 1999, n. P. LXXVII/99, 1999.

70 Vienna Convention on the Law of Treaties. 1155 U.N.T.S. 331. Vienna: United Nations. 1969.

71 SCJN. Supremacía constitucional. La reforma al artículo 1 o de la Constitución Política de los Estados Unidos Mexicanos, de 10 de junio de 2011, respeta este principio. [TA]; 10a. Época; 2a. Sala; S.J.F. y su Gaceta, Libro XIII, Octubre de 2012, Tomo 3, n. 2a. LXXV/2012 (10a.). 2012.
} 
el principio de supremacía constitucional, e, indirectamente, la visión dominante de la jerarquía normativa. $^{72}$

Las nuevas narrativas después de la C.T. 293/11, en suma, reconocen la supremacía de las normas de derechos humanos cuando éstas sean más favorables para la persona. Empero, sostienen que son los derechos humanos incluidos en tratados internacionales los que se insertan al catálogo de derechos constitucionales, gozando así de supremacía constitucional, pero no así los tratados como tal. En este sentido, los derechos se desvinculan de su fuente al integrarse al catalogo constitucional, por lo que no puede decirse que son los tratados los que gozan de jerarquía constitucional, sino los derechos que contienen. Asimismo, aunque los jueces siempre deben buscar la interpretación más favorable, sin importar la fuente de la garantía, la Constitución permanece como norma fundamental, lo que implica que el resto de las normas deben ser acordes con la misma. Entonces, cuando haya, en la norma fundamental, una restricción expresa al ejercicio de los derechos humanos, aunque provengan de tratados internacionales, se deberá estar a lo que indica la Constitución. ${ }^{73}$

\section{REFLEXIONES SOBRE LAS 'NUEVAS’ NARRATIVAS DE LA SUPRE- MACÍA CONSTITUCIONAL Y DE LA JERARQUÍA NORMATIVA EN MÉXICO}

La reforma al artículo primero constitucional cambió el contexto de la interpretación de los derechos humanos en México, y, como vimos anteriormente, generó conflictos sobre cómo interpretar los tratados de derechos humanos respecto al artículo 133 constitucional.

La Corte concluyó que la reforma al artículo primero amplió el catálogo de derechos humanos previsto en la Constitución, los cuales se fusionan en una suerte de bloque de supremacía constitucional, en el que los derechos humanos comparten supremacía con otras normas constitucionales, de manera que, al referirse a derechos provenientes de ordenamientos internacionales, es como si se estuviera refiriendo a los derechos contenidos en la misma Constitución. En este sentido, las normas de derechos humanos, sin importar su fuente, deben acatar y seguir la suerte de cualquier disposición constitucional, respetando las reglas de validez y ejercicio establecidas por ella.

\footnotetext{
72 Posteriormente, el Pleno de la Suprema Corte, como ya mencioné, analizaría nuevamente la jerarquía de los tratados internacionales respecto de la Constitución en la C.T. 293/11.

73 Contradicción de Tesis 293/2011. SCJN. Gaceta del Semanario Judicial de la Federación, Libro 5, Tomo I, 2013.
} 
Seguido de esto, cualquier restricción expresa al ejercicio de derechos humanos dentro de la Constitución, prevalecería sobre el tratado internacional que contenga la norma restringida y sobre la norma en sí.

Ahora bien, la Suprema Corte estableció que la conformidad de las normas internacionales de derechos humanos con la Constitución, para efectos de su incorporación al ordenamiento jurídico, debe cumplir con "el requisito de validez material de naturaleza especial" previsto en el artículo quince constitucional-exigido únicamente respecto a tratados que contengan normas de derechos humanos-, de que su contenido no menoscabe el catálogo constitucional de derechos. ${ }^{74}$

Aquí, la Corte establece otro criterio fundamental, esto es, la desvinculación del derecho humano de su fuente. En este sentido, las normas específicas, y no el tratado en su conjunto, se integran al "parámetro de regularidad" contenido en el artículo primero constitucional. De tal forma, dichas normas se convierten en parte del "catálogo constitucional de derechos", desvinculándose de su fuente y su jerarquía normativa, para, así, gozar de supremacía constitucional. ${ }^{75}$

[E]l catálogo de derechos humanos comprende tanto los que se encuentran expresamente reconocidos en la Constitución como aquéllos contemplados en los tratados internacionales ratificados por el Estado mexicano. En este orden de ideas, la supremacía constitucional se predica de todos los derechos humanos incorporados al ordenamiento mexicano, en tanto forman parte de un mismo catálogo o conjunto normativo. Esta conclusión se refuerza con el mandato expreso del Poder Reformador de permitir que los derechos humanos de fuente internacional puedan ser empleados como parámetro de validez del resto de las normas jurídicas del ordenamiento jurídico mexicano, dentro de las cuales se incluyeron expresamente los propios instrumentos internacionales. ${ }^{76}$

Razonando sobre el argumento anterior, la Suprema Corte se cuestiona: ¿cómo es posible que una norma, cuya existencia y validez depende de la Constitución, establezca junto con normas constitucionales, el parámetro de control de la validez de todas las demás normas del ordenamiento jurídico?

En respuesta, la Corte propone "la disociación de dos momentos". Esto es, concebir un primer momento en que el instrumento internacional se incorpora al orden jurídico tras haber cumplido con los requisitos formales de validez establecidos en la

\footnotetext{
74 El artículo quince constitucional estipula: “Los derechos y libertades reconocidos en el Capítulo Segundo del presente Título vinculan a todos los poderes públicos. Sólo por ley, que en todo caso deberá respetar su contenido esencial, podrá regularse el ejercicio de tales derechos y libertades, que se tutelarán de acuerdo con lo previsto en el artículo 161, 1, a)".

75 Contradicción de Tesis 293/2011. SCJN. Gaceta del Semanario Judicial de la Federación, Libro 5, Tomo I, 2013.

76 Contradicción de Tesis 293/2011. SCJN. Gaceta del Semanario Judicial de la Federación, Libro 5, Tomo I, 2013.
} 
Constitución; y un segundo momento en que, una vez incorporado al orden jurídico, debe satisfacer requisitos materiales de validez, es decir, la conformidad del tratado con la Constitución, entendida como que el instrumento internacional "no contraríe las normas constitucionales y específicamente que no afecte los derechos humanos previstos en la propia Constitución y en otros tratados internacionales".

En este razonamiento la Corte distingue entre "dos dimensiones de la regularidad normativa", la "'vigencia' o 'existencia"' de las normas, o validez formal; y su validez material. Así, "el incumplimiento de los requisitos de forma conduciría a concluir que un tratado internacional no es derecho vigente en México", mientras que "la no satisfacción de los requisitos materiales obligaría a declarar su invalidez".77 Respecto a la validez material, la Corte establece lo siguiente:

[P] uede decirse que el requisito previsto en el artículo 133 constitucional refuerza la interpretación de que los tratados internacionales se encuentran en una posición jerárquica inferior a la Constitución, mientras que el requisito previsto en el artículo 15 constitucional garantiza que, con independencia de la jerarquía normativa del instrumento que las reconozca, las normas internacionales de derechos humanos, y no el tratado en su conjunto, se integren al parámetro de regularidad contenido en el artículo $1^{\circ}$ constitucional. ${ }^{78}$

Lo anterior puede leerse como que sólo los derechos específicos contenidos en un tratado internacional, que cumplan con el requisito material, entran al catálogo constitucional, desvinculándose de su fuente y de su jerarquía normativa, para gozar de supremacía constitucional. Según la Corte, su interpretación de la dimensión de validez material coincide plenamente con el principio de progresividad de los derechos humanos, ya que su incorporación se debe analizar conforme a los principios de interpretación conforme y de progresividad, así como con el principio pro persona. ${ }^{79}$

Sin embargo, lo anterior no queda claro, ya que la Corte estaría sugiriendo que, dentro de un análisis sobre la dimensión de validez material de una norma de fuente internacional, ésta se debe someter a un análisis de proporcionalidad o a una máxima de racionalidad como lo es el principio pro persona. ${ }^{80}$ Lo anterior, permitiría asumir que, en última instancia, si una norma de fuente internacional ofrece mayor protección o restringe en menor medida un derecho humano, entonces podría prevalecer por

77 Contradicción de Tesis 293/2011. SCJN. Gaceta del Semanario Judicial de la Federación, Libro 5, Tomo I, 2013.

78 Contradicción de Tesis 293/2011. SCJN. Gaceta del Semanario Judicial de la Federación, Libro 5, Tomo I, 2013.

79 Contradicción de Tesis 293/2011. SCJN. Gaceta del Semanario Judicial de la Federación, Libro 5, Tomo I, 2013.

80 CIANCIARDO, Juan. El ejercicio regular de los derechos: Análisis y crítica del conflictivismo. 1. ed. Buenos Aires: AdHoc, 2007, p. 285-287. 
encima, incluso, de la norma constitucional restrictiva. Sin embargo, la conclusión de la Corte en este punto establece precisamente lo contrario.

El bloque de supremacía constitucional que plantea la Suprema Corte funciona como un escudo que opera en dos momentos. Primero, al momento del análisis de validez material de un tratado internacional que se incorpora al marco jurídico mexicano, ubicando, a priori, a la fuente internacional del derecho en cuestión, por debajo de la Constitución, solucionando cualquier argumentación sobre la jerarquía normativa superior del instrumento internacional. En un segundo momento, una vez que se extrajo al derecho del instrumento en cuestión, es decir, una vez que se le desvinculó de su fuente y se le incluyó en el bloque de supremacía constitucional, éste funciona para someter al derecho a un análisis de su validez frente $a$, y en relación con otros derechos y disposiciones constitucionales, incluidas las restricciones a su ejercicio. Ahora bien, la Corte no es clara en este sentido, es decir, no establece criterios claros, y parece que el segundo nivel de análisis de validez material se limita a un criterio meramente formal, o sea, que la limitación a un derecho sólo deba contar con rango constitucional. ${ }^{81}$

Esto contradice el argumento de que las normas internacionales, además, se deben interpretar conforme al principio pro persona, ya que se adelanta a dar la solución sin permitir un análisis de proporcionalidad y razonabilidad. Es decir, en el caso de la limitación o restricción a un derecho, la Corte emite una fórmula que elimina la posibilidad de cualquier análisis crítico-como sería el principio pro persona-al decretar que todo juzgador deberá otorgar preferencia a una limitación constitucional, por encima del derecho mismo.

En la misma lógica, con la estructuración del bloque de supremacía constitucional, se genera una problemática esencial con relación a conflictos normativos en materia de derechos humanos, la cual cuenta con dos aristas: 1) a pesar de reconocer que los derechos humanos se deben interpretar de conformidad con la Constitución y los tratados internacionales "favoreciendo en todo tiempo a las personas la protección más amplia", la Corte interpreta la aplicabilidad de normas de fuente internacional-incluidas las de derechos humanos—bajo criterios de jerarquía normativa entre el derecho

\footnotetext{
81 Vale la pena aquí reflexionar sobre la experiencia de otros regímenes constitucionales en materia de restricción de derechos fundamentales. En el caso alemán, por ejemplo, la Ley Fundamental establece todo un artículo sobre la limitación de derechos: “Artículo 19. Restricción de los derechos fundamentales. (1) Cuando de acuerdo con la [...] Ley Fundamental un derecho fundamental pueda ser restringido por ley o en virtud de una ley, ésta deberá tener carácter general y no estar limitada al caso individual. Además, la ley deberá mencionar el derecho fundamental indicando el artículo correspondiente. (2) En ningún caso un derecho fundamental podrá ser afectado en su contenido esencial [...]", Ley Fundamental de la República Federal de Alemania. Alemania: Boletín Oficial Federal. 1949. Por otro lado, el artículo 53.1 de la Constitución Española establece: "Los derechos y libertades reconocidos en el Capítulo Segundo del presente Título vinculan a todos los poderes públicos. Sólo por ley, que en todo caso deberá respetar su contenido esencial, podrá regularse el ejercicio de tales derechos y libertades, que se tutelarán de acuerdo con lo previsto en el artículo 161, 1, a), Constitución Española. España: 1978. En ambos casos, la regulación o limitación de derechos fundamentales depende del requisito material de contenido esencial.
} 
internacional y el derecho interno, es decir, zanja el viejo debate de las jerarquías, confirmando la hegemonía de la Constitución y reafirmando el principio de supremacía constitucional; y 2) despoja a los derechos de su fuente, los somete a un segundo nivel de análisis de validez material, que no es necesariamente claro, pero que parece apelar a una simple dimensión formal, que, al final, anula la capacidad de resistencia a la restricción, propia de los derechos humanos, y con ello, además, limita la naturaleza operativa crítica del principio pro persona.

\section{CONSIDERACIONES FINALES}

Sin duda, la postura mantenida por México respecto al papel del derecho internacional dentro del derecho interno contrasta con su actividad en el plano internacional donde ha firmado y ratificado una gran cantidad de tratados internacionales, muchos de ellos en materia de derechos humanos. Además de estar vinculado a los tratados relativos, México es miembro activo de organizaciones internacionales como la ONU-y sus organismos-así como otros organismos regionales como la Comisión Interamericana de Derechos Humanos, además de haber aceptado la competencia contenciosa de la Corte IDH. ${ }^{82}$

Sin duda, la actitud de México respecto a sus obligaciones en materia de derechos humanos refleja un cierto desequilibrio jurídico-institucional, ya que, por un lado, la firma de tratados y la aprobación de reformas que tienden a ser mayormente garantistas, van seguidas de regulaciones represivas o interpretaciones limitativas, como ya apunté anteriormente.

A pesar de los virajes legislativos y jurisprudenciales, México parece confirmar, en última instancia, un sistema jurídico relativamente rígido. Su proactividad en el orden jurídico internacional a veces contrasta con un cierto proteccionismo de las interpretaciones tradicionales y originalistas del texto constitucional vigente desde $1917,{ }^{83}$ y su interpretación vis-á-vis el derecho internacional, genera criterios equívocos y discordantes, pero siempre refrenda una visión tradicionalista de la supremacía constitucional. ${ }^{84}$

82 México depositó el instrumento de ratificación-o adhesión- de la Corte IDH el 24 de marzo de 1981, sin embargo, su jurisdicción no fue aceptada inmediatamente. La aceptación de la jurisdicción contenciosa se produjo hasta el 16 de diciembre de 1998.

83 La vigencia del texto constitucional debe matizarse con la aclaración de las múltiples reformas que ha sufrido. Hasta agosto del año 2020, México había emitido 242 decretos de reforma que se han traducido en cambios a varios artículos del texto fundamental, desde la Primera hecha por Álvaro Obregón del artículo 73 y el decimocuarto transitorio en 1921, hasta la reforma del artículo cuarto por Andrés Manuel López Obrador en 2020. CÁMARA DE DIPUTADOS. Reformas Constitucionales. México, 2020. Disponible en: <http://www. diputados.gob.mx/LeyesBiblio/ref/cpeum_crono.htm>. Acesso en: Sep. 16.

84 Existen posturas que buscan acercar principios tradicionales como el de supremacía constitucional a una nueva realidad globalizada. Por ejemplo, Ferrajoli, plantea repensar el constitucionalismo, ante la necesidad de diseñar garantías constitucionales tanto a nivel nacional como supranacional, y propone el constitucionalismo 
Aunque en materia de derechos humanos las disposiciones constitucionales han tendido a ser mayormente receptivas de las normas internacionales, se ha refrendado la jerarquía inferior del derecho internacional y se ha mantenido siempre incólume el principio de tradicional de supremacía constitucional. Más aún, se ha reivindicado la posibilidad de establecer de manera constitucional restricciones a los derechos humanos en afrenta a instrumentos internacionales obligatorios para México. Esta postura se contrapone a la Convención Americana en su artículo 29, que es específica en no permitir la supresión del goce y ejercicio de los derechos y libertades, o limitarlos en mayor medida que la prevista en ella; o bien limitar el goce y ejercicio de cualquier derecho o libertad que pueda estar reconocido de acuerdo con las leyes de los Estados Partes o de acuerdo con otro instrumento internacional. ${ }^{85}$

Al final, las visiones de cómo México debe afrontar sus obligaciones internas e internacionales en materia de derechos humanos resultan opuestas y contradictorias. El derecho constitucional mexicano parece querer mantener una postura rígida ante el derecho internacional, y a pesar de la consolidación global de los derechos humanos y del derecho internacional, los interpretes constitucionales parecen seguir concibiendo a este último como normatividad de segundo grado. ${ }^{86}$

\section{REFERENCIAS}

ARTEAGA NAVA, Elisur. Derecho Constitucional. 2. ed. México: Oxford University Press, 2001.

BURGOA, Ignacio. Derecho Constitucional Mexicano. 8. ed. México: Porrúa, 1991.

CÁMARA DE DIPUTADOS. Reformas Constitucionales. México, 2020. Disponible en: <http:// www.diputados.gob.mx/LeyesBiblio/ref/cpeum_crono.htm>. Acceso: Sep. 16.

CARPIZO, Jorge. La interpretación del artículo 133 constitucional. Boletín Mexicano de Derecho Comparado, Nueva Serie, año II, n. 4, ene./abr., 1969.

CIANCIARDO, Juan. El ejercicio regular de los derechos: Análisis y crítica del conflictivismo. 1. ed. Buenos Aires: AdHoc, 2007.

CRAWFORD, James. Brownlie's Principles of Public International Law. 8 ed. Oxford: Oxford University Press, 2012.

global FERRAJOLI, Luigi. Más allá de la soberanía y la ciudadanía: un constitucionalismo global. In: CARBONELL, Miguel (Ed.). Teoría de la Constitución. México: Porrúa, 2000. p. 397, passim. A su vez, Habermas plantea la cuestión de un constitucionalismo global, HABERMAS, Jürgen. Plea for a constitutionalization of international law. Philosophy and Social Criticism, vol. 40, n. 1, p. 5-12, 2014, passim. Zagrebelsky propone a su vez una reconstrucción que de lugar a un nuevo constitucionalismo dúctil. ZAGREBELSKY, Gustavo. El derecho dúctil. 3. ed. Madrid: Trotta, 1999, passim.

85 Convención Americana de Derechos Humanos (Pacto de San José) San José: Organización de los Estados Americanos. 1969.

86 ARTEAGA NAVA, Elisur. Derecho Constitucional. 2. ed. México: Oxford University Press, 2001, p. 21-23. 
DOUZINAS, Costas. The End of Human Rights. Oxford: Hart Publishing, 2000.

FERRAJOLI, Luigi. Más allá de la soberanía y la ciudadanía: un constitucionalismo global. In: CARBONELL, Miguel (Ed.). Teoría de la Constitución. México: Porrúa, 2000.

GEARTY, Conor. Spoils for which victor? Human rights within the democratic state. In: GEARTY, Conor; DOUZINAS, Costas (Ed.). The Cambridge Companion to Human Rights Law. New York: Cambridge University Press, 2012.

HABERMAS, Jürgen. Plea for a constitutionalization of international law. Philosophy and Social Criticism, vol. 40, n. 1, p. 5-12, 2014.

KELSEN, Hans. Principles of International Law. 2. ed. New York: Holt, Rinehart and Winston, 1966. NACIONES UNIDAS. Vienna Convention on the Law of Treaties. O.N.U.: May 23. 1969.

RAMSEY, Michael D. The Supremacy Clause, Original Meaning, and Modern Law. Ohio State Law Journal, vol. 74, n. 4, 2013.

RODRÍGUEZ FERREIRA, Octavio. El nuevo sistema penal acusatorio en México. In: OCTAVIO RODRÍGUEZ FERREIRA; SHIRK, David A. (Ed.). La reforma al sistema de justicia penal en México. San Diego: Justice in Mexico, University of San Diego, 2013.

SAMAR, Vincent. Two Understandings of Supremacy: An Essay. Richmond Journal of Global Law and Business, vol. 9, n. 4, p. 339-380, 2010.

SHIRK, David. Criminal Justice Reform in Mexico: An Overview. Mexican Law Review, vol. 3, n. 2, p. 189-228, 2011.

SHIRK, David A. Reforma de la Justicia Penal en México. In: RODRÍGUEZ FERREIRA, Octavio; SHIRK, David (Ed.). La reforma al sistema de justicia penal en México. San Diego: Justice in Mexico, 2013.

TENA RAMÍREZ, Felipe. Leyes Fundamentales de México 1808 - 1997. 20. ed. México: Porrúa, 1997.

TENA RAMÍREZ, Felipe. Derecho Constitucional Mexicano. 32. ed. México: Porrúa, 1998.

ZAGREBELSKY, Gustavo. El derecho dúctil. 3. ed. Madrid:Trotta, 1999.VILLORO, Luis. Sobre el principio de injusticia: la exclusión. Isegoría. Revista de Filosofía, Moral y Política, n. 22, p. 103-142, 2000. 